\title{
Carbon Supported Gold Nanoparticles for the Catalytic Reduction of 4-Nitrophenol
}

\author{
Hugo Rodríguez Molina ${ }^{1}$, José Luis Santos Muñoz ${ }^{1}$, María Isabel Domínguez Leal ${ }^{1}$, \\ Tomas Ramírez Reina ${ }^{2}$, Svetlana Ivanova ${ }^{1 *}$, Miguel Ángel Centeno Gallego ${ }^{1}$ and \\ José Antonio Odriozola ${ }^{1}$
}

1 Departamento de Química Inorgánica, Instituto de Ciencia de Materiales de Sevilla, Seville, Spain, ${ }^{2}$ Department of Chemical and Process Engineering, Faculty of Engineering and Physical Sciences, University of Surrey, Guildford, United Kingdom

\section{OPEN ACCESS \\ Edited by: \\ Hadi Nur, \\ University of Technology \\ Malaysia, Malaysia \\ Reviewed by: \\ Zhihua Xu, \\ Jianghan University, China Tomoo Mizugaki, \\ Osaka University, Japan \\ *Correspondence: \\ Svetlana Ivanova \\ svetlana@icmse.csic.es}

Specialty section: This article was submitted to Catalysis and Photocatalysis, a section of the journa

Frontiers in Chemistry

Received: 08 May 2019

Accepted: 19 July 2019

Published: 16 August 2019

Citation:

Rodríguez Molina H, Santos

Muñoz JL, Domínguez Leal MI,

Reina TR, Ivanova S, Centeno Gallego MÁ and Odriozola JA (2019) Carbon Supported Gold Nanoparticles for the Catalytic Reduction of 4-Nitrophenol.

Front. Chem. 7:548.

doi: 10.3389/fchem.2019.00548
This work is a detailed study on how to optimize gold colloids preparation and their deposition to very different in nature carbon materials. The change of the continuous phase and its dielectric constant is used to assure the good dispersion of the hydrophilic/hydrophobic carbons and the successful transfer of the preformed small size colloids to their surface. The sintering behavior of the particles during the calcination step is also studied and the optimal conditions to reduce to a minimum the particle size increase during the protecting agent removal phase are found. The as prepared catalysts have been tested in a relevant reaction in the field of environmental catalysis such as the reduction of 4-nitrophenol leading to promising results. Overall, this work proposes an important methodology to follow when a carbonaceous material are selected as catalyst supports for green chemistry reactions.

Keywords: gold colloids, carbon, reduction, 4-nitrophenol, size effect

\section{INTRODUCTION}

Noble metal nanoparticles (NPs) remain one of the fast-growing fields in material science, due to their importance for optical, electrical, magnetic and catalytic technologies. All applications are based on nanoparticle's versatility due to their special size-morphology-properties relationship. Its massive use, however, is limited by geopolitical distribution and cost, disadvantages resolved by supporting preformed NPs on more sustainable materials such as polymers, organic molecules, inorganic structures and/or carbons. In this manner, NPs properties are preserved and the quantity of noble metal in the final material reduced (Goesmann and Feldmann, 2010; Tan et al., 2013; Chairam et al., 2017). Sometimes, NPs- support interaction occurs resulting in beneficial effect on material' overall properties. A good example is the integration of carbonaceous materials, i.e., graphene, carbon nanotubes, or activated carbons as supports for noble metals, where the support electrochemical, electrical, and catalytic properties are affected by the presence of metal (Tan et al., 2013). Activated carbon is a particularly important support for catalytic industry because of its high specific surface and stability in acidic/basic conditions and at moderate to high temperatures in low oxidizing atmospheres. Even more, its variable porous structure and low cost makes viable its use in many catalytic applications, especially in liquid phase reactions (Rodríguez-Reinoso, 1998). 
An important part of the sustainability is the conversion of existing technologies, chemical industry in particular, in safer environmentally friendly processes. This could be achieved with the reduction of greenhouse gas emission and minimization of all toxic wastes. A worrying amount of hazardous wastewaters, generated daily, need expensive processing for minimization and/or transformation of all toxic residues to less dangerous products. Different pollutants such as dyes, heavy metals, or phenols and their derivatives are of great concern (Zhang et al., 2003; Chatterjee and Dasgupta, 2005; Menumerov et al., 2016). 4nitrophenol (4-NP) is an example of harmful group of chemicals (phenols and derivatives) used in fungicides, medicines, dyes, and leather manufacture. It is known to be carcinogenic and mutagenic and causes skin diseases (Harrison et al., 2005; Zhao et al., 2010). Therefore, removal of 4 -NP from waste water is key to ensure a healthy environment. However, its removal is a tedious process; physical, chemical, and biological treatments have to be used for this purpose.

The catalytic reduction of 4-NP in the presence of sodium borohydride $\left(\mathrm{NaBH}_{4}\right)$ has emerged as a key process based on its simplicity, low cost and usefulness of the reaction product, 4-aminophenol (4-AP) (Du et al., 2004; Wunder et al., 2011; Hervés et al., 2012). 4-AP is non-toxic and widely used in pharmaceutical industry for analgesics and antipyretics, like paracetamol, phenacetin, etc. (Alif and Boule, 1991; Shi et al., 2005). This reduction is a catalytic process and supported noble nanoparticles are often reported as catalyst (Saha et al., 2009; Wunder et al., 2010). Among them, gold showed great selectivity and activity (Kuoda et al., 2009) and a special structure-size sensitivity that allows to study particles nitroarene hydrogenation activity and its proportionality to totally exposed particle surface (Kuoda et al., 2009; Lin and Doong, 2014).

To do this, an important size control is needed and referring to gold is not an easy task. One of the methods that allows a control over nanoparticles size and morphology is the colloidal route, where a gold colloid, freshly prepared, transfers to a support (Luo et al., 2013). To immobilize successfully the preformed colloids, we need to consider support nature and its hydrophilic/hydrophobic properties in particular for carbon based materials and its dispersability in the continuous phase.

For all described above, this work focuses on optimization of the gold colloids preparation and transfer to carbon based materials of different nature with the final aim to produce homogeneous and well dispersed gold nanoparticles based catalysts for 4-nitrophenol reduction in aqueous media. This work organizes around three approaches: (i) effect of solvent nature, (ii) effect of catalysts calcination parameters, and (iii) carbon nature influence on the catalytic properties.

\section{EXPERIMENTAL}

\section{Synthesis of Au/C Catalysts}

The experimental approach is based on the reduction of a gold precursor in the presence of stabilizing agent that allows particle size control. Once obtained the nanoparticles are transferred to the carbonaceous support (Megías-Sayago et al., 2018).
In a typical preparation, required amount of gold precursor ( $\mathrm{HAuCl}_{4}$, Johnson Matthey, 49, 81\% Au) was dissolved at room temperature in the continuous phase (water or water-ethanol mixture) with $5.10^{-4} \mathrm{M}$ final gold concentration. Polyvinyl alcohol (PVA, Sigma Aldrich, 98\%) 1\% wt aqueous solution was used as stabilizing agent in $\mathrm{PVA} / \mathrm{Au}=0.85$ weight ratio. After $20 \mathrm{~min}$ of continuous stirring, an adequate volume of $0.1 \mathrm{M} \mathrm{NaBH}_{4}$ (Sigma Aldrich, 98\%) solution $\left(\mathrm{NaBH}_{4} / \mathrm{Au}=10\right.$ molar ratio) was added to reduce rapidly the gold precursor and the resulting nanoparticles are kept under stirring for 20 more min. After, the colloid was immobilized on appropriate quantity of a commercially available activated carbon (CD) DARCO ${ }^{\circledR}$ (Sigma Aldrich, 100 mesh particle size) to obtain 2\% wt of gold in the final sample. The anchorage of the colloid on carbon surface was ensured by keeping both in contact until complete discoloration of the solution. Final suspension was filtered, washed with water or ethanol (depending on the solvent mixture used during the synthesis) dried at $100^{\circ} \mathrm{C}$ and finally calcined at $300^{\circ} \mathrm{C}$.

Different water-ethanol mixtures were used as preparation media in order to study the effect of the solvent nature. Table 1 summarizes the solvent mixtures and the nomenclature of the resulting catalysts.

For the optimization of the calcination step and PVA elimination, different calcination procedures were employed in order to avoid nanoparticles sintering (Table 2). For all methods, the temperature $\left(300^{\circ} \mathrm{C}\right)$ and gas total flow $(30 \mathrm{~mL} / \mathrm{min})$ remain constant.

TABLE 1 | Catalyst nomenclature and solvent mixture used in the synthesis.

\begin{tabular}{lc}
\hline Catalyst & Water:ethanol $\%(\mathbf{v} / \mathbf{v})$ \\
\hline Au/CD_100 & $100: 0$ \\
Au/CD_70 & $70: 30$ \\
Au/CD_50 & $50: 50$ \\
Au/CD_30 & $30: 70$ \\
Au/CD_8 & $8: 92$
\end{tabular}

TABLE 2 | Tested calcination process over Au/CD_100 sample.

\begin{tabular}{|c|c|c|c|c|c|c|}
\hline \multirow[t]{2}{*}{ Method } & \multirow[t]{2}{*}{ Catalyst } & \multirow[t]{2}{*}{ Time } & \multicolumn{3}{|c|}{ Atmosphere } & \multirow{2}{*}{$\begin{array}{c}\text { Heating } \\
\text { rate } \\
\left({ }^{\circ} \mathrm{C} / \mathrm{min}\right)\end{array}$} \\
\hline & & & Heating & Combustion & Cooling & \\
\hline 1 & Au/CD_100 & $2 \mathrm{~h}$ & S.A. & S.A. & S.A. & 10 \\
\hline 2 & $\mathrm{Au} / \mathrm{CD} \_100$ & $2 \mathrm{~h}$ & $\begin{array}{c}\mathrm{N}_{2} / \mathrm{S} . \mathrm{A} . \\
(2 \% \text { S.A.) }\end{array}$ & $\begin{array}{c}\mathrm{N}_{2} / \mathrm{S} . \mathrm{A} . \\
(2 \% \text { S.A.) }\end{array}$ & $\begin{array}{l}\mathrm{N}_{2} / \text { S.A. } \\
(2 \% \text { S.A.) }\end{array}$ & 10 \\
\hline 3 & Au/CD_100 & $30 \mathrm{~min}$ & $\begin{array}{l}\mathrm{N}_{2} / \mathrm{S} . \mathrm{A} . \\
(2 \% \text { S.A.) }\end{array}$ & $\begin{array}{l}\mathrm{N}_{2} / \text { S.A. } \\
(2 \% \text { S.A.) }\end{array}$ & $\begin{array}{l}\mathrm{N}_{2} / \text { S.A. } \\
(2 \% \text { S.A.) }\end{array}$ & 10 \\
\hline 4 & Au/CD_100 & $2 \mathrm{~h}$ & $\mathrm{~N}_{2}$ & S.A. & $\mathrm{N}_{2}$ & 10 \\
\hline 5 & Au/CD_100 & $2 \mathrm{~h}$ & $\mathrm{~N}_{2}$ & $\begin{array}{l}\mathrm{N}_{2} / \text { S.A. } \\
(2 \% \text { S.A.) }\end{array}$ & $\mathrm{N}_{2}$ & 10 \\
\hline 6 & Au/CD_100 & $30 \mathrm{~min}$ & $\begin{array}{c}\mathrm{N}_{2} / \mathrm{S} . \mathrm{A} . \\
(2 \% \text { S.A.) }\end{array}$ & $\begin{array}{c}\mathrm{N}_{2} / \mathrm{S} . \mathrm{A} . \\
(2 \% \text { S.A. })\end{array}$ & $\begin{array}{c}\mathrm{N}_{2} / \mathrm{S} . \mathrm{A} . \\
(2 \% \text { S.A.) }\end{array}$ & 2 \\
\hline
\end{tabular}

Combustion temperature $=300^{\circ} \mathrm{C}$, Gas total flow $=30 \mathrm{~mL} / \mathrm{min}$. S.A. = Synthetic air. 
Taking as reference the conditions used in previous works (method 1, Table 2; Megías-Sayago et al., 2018) atmosphere composition, time and heating rate were varied to evaluate their influence on average gold particle size. The combustion of PVA in synthetic air is an exothermic process and could favor gold nanoparticles sintering facilitated even more by weak metal-support interaction (Au-C). All steps of the calcination process, separated in heating-combustion-cooling were carried out in low oxygen atmosphere (methods 2, 3, 6) to reduce the exothermicity of the process and minimize gold sintering. Pure nitrogen flow was also used during heating and cooling steps (methods 4 and 5) to improve presumably the annealing process, during which the protective agent is converted in a surface carbon layer covering the gold particle but allowing stronger metal-support interactions and decrease of the sintering rate (Zhan et al., 2017). Oxygen contact time was varied during the calcination step or by decreasing the heating rate (methods 3 and 6).

\section{Charcoal Powder Support Variation}

The optimized synthesis procedure including calcination process described in method 3 was employed to prepare a new series of $\mathrm{Au} / \mathrm{C}$ catalysts with different charcoal supports. Depending on the hydrophilic properties of the charcoals, different water-ethanol mixtures were used (Table 3). The used charcoals are:

- Carbon obtained by pyrolysis of commercial microcrystalline cellulose in $\mathrm{CO}_{2}$ atmosphere (CC) (Santos et al., 2018a).

- Carbon obtained by pyrolysis of wine shoot previously demineralized with nitric acid in $\mathrm{CO}_{2}$ atmosphere (CS).

- Carbon obtained after $4 \mathrm{M}$ nitric acid (room temperature, $4 \mathrm{~h}$ ) treatment of CS sample (CSA).

The selected charcoals present different textural and hydrophilic characteristics and allow to investigate the influence of support properties on the final catalyst.

\section{Characterization Techniques}

XRD analysis were carried out on Panalitycal X'Pert Pro diffractometer, equipped with $\mathrm{Cu}$ anode. Diffractograms were recorded with $0.05^{\circ}$ step size and $300 \mathrm{~s}$ acquisition time in the $10-90^{\circ} 2 \theta$ range.

PHILIPS CM-200 was used for the transmission electron microscopy (TEM) measurements of the initial gold colloids

TABLE 3 | Nomenclature and water-ethanol mixtures employed.

\begin{tabular}{lc}
\hline Catalyst & Water:ethanol \% (v/v) \\
\hline Au/CC_8_3 & $8: 92$ \\
Au/CC_30_3 & $30: 70$ \\
Au/CS_8_3 & $8: 92$ \\
Au/CS_30_3 & $30: 70$ \\
Au/CS_100_3 & $100: 0$ \\
Au/CSA_30_3 & $30: 70$ \\
Au/CSA_100_3 & $100: 0$
\end{tabular}

and the final $\mathrm{Au} / \mathrm{C}$ samples. The average gold particle size is determined taking into account particles surface distribution (Equation 1).

$$
D[3,2]=\frac{\sum_{1}^{n} D_{i}^{3} v_{i}}{\sum_{1}^{n} D_{i}^{2} v_{i}}
$$

where Di is the geometric diameter of the $i$ th particle, and $v i$ the number of particles with this diameter. For every distribution, the number of measured particles overcomes 200 particles per sample.

UV-Vis spectra were acquired on Cary 300 UV-Vis spectrometer equipped with optic fiber liquid sensor for wavelengths ranged between 190 and $900 \mathrm{~nm}$ and 5 absorbance units working range to measure turbid and solid liquid samples.

Raman spectra were recorded using dispersive Horiba Jobin Yvon LabRam HR800 microscope with a He-Ne green laser $(\lambda$ $532.14 \mathrm{~nm}$ ) working at $20 \mathrm{~mW}$ with $600 \mathrm{~g} \mathrm{~mm}^{-1}$ grating, $50 \times$ objective and a confocal pinhole of $1,000 \mu \mathrm{m}$.

DRIFTS spectra were obtained at room temperature without sample dilution, using a JASCO FTIR 6200 spectrometer equipped with an accessory DRIFTS Pike EASI-DIFF. Each spectrum was recorded accumulating 100 scans with resolution of $4 \mathrm{~cm}^{-1}$.

\section{Catalytic Tests}

For the reduction of 4-nitro to 4-aminophenol at room temperature with $\mathrm{NaBH}_{4}$ three separate solutions were prepared: (i) $2.5 \mathrm{mg}$ of catalyst dispersed in $10 \mathrm{~mL}$ of water, (ii) $0.39 \mathrm{~g}$ of $\mathrm{NaBH}_{4}$ dissolved in $10 \mathrm{~mL}$ of water, and (iii) $28.4 \mathrm{mg}$ of 4-nitrophenol (Sigma Aldrich, 99\%) dissolved in $10 \mathrm{~mL}$ of water. A final volume of $30 \mathrm{ml}$ was obtained after contacting all three solutions in the order (i) (catalyst) + (ii) $\left(\mathrm{NaBH}_{4}\right)$ + (iii) (4-nitrophenol), and reaction time 0 was considered. Aliquots samples of $1 \mathrm{~mL}$ was extracted at different reaction times and analyzed by UV-Vis spectroscopy, where the evolution of the absorption band centered at $400 \mathrm{~nm}$ (corresponding to 4nitrophenolate ions) was followed until disappearance. AvaLightDH-S-BAL UV-Vis spectrometer UV-Vis equipped with fiber optic liquid sensor was used for these measurements.

\section{RESULTS AND DISCUSSION}

\section{Influence of the Solvent Nature}

The mixture of two solvents with different polarity (water and ethanol in our case) allows the adjustment of the dielectric constant of the medium according to the hydrophilic/hydrophobic behavior of the carbon material. However, the presence of two solvents will influence the colloid behavior and most probably the final gold particle size. In order to evaluate the extension of this effect, UV-Vis study of the colloids obtained in different solvent mixtures was carried out.

The UV-Vis spectra for all colloids show maximum absorption between 520 and $540 \mathrm{~nm}$ (Figure 1), corresponding to the characteristic range of surface plasmon resonance (SPR) of gold nanoparticles. It is known that SPR position, area and intensity depend on the size and shape of the gold 
nanoparticles as well as on the dielectric constant of the medium (Bond and Thompson, 1999).

Generally, an increase in particle size implies a redshift of SPR and an increase in the area of absorption peak (Bond and Thompson, 1999). The estimated values of the wavelength of maximal absorbance and calculated area (400-700 $\mathrm{nm}$ range) indicate that a continuous increment of ethanol concentration produces a redshift and SPR area increase, suggesting particle size growth (Table 4). Only the colloid generated at a water:ethanol 50:50 ratio escapes from the tendency.

The average gold particle size studied by TEM microscopy as a function of solvent nature is resumed in Table 4.

The tendency observed by UV-Vis is confirmed by TEM, higher the ethanol concentration higher the average particle size (Figure 2) exception made by 50:50 sample, which presents an exceptional higher value. As for the distribution of sizes, the colloids with smaller average particle size present narrower size distribution than those with larger average particle size. The Gaussian distribution becomes less symmetric with the increase of the average particle size. Macroscopically, the colloids with smaller average particle size are reddish, while those with a larger average particle size purple, in agreement with previous studies by Bond and Thompson (1999).

The dielectric constant of the solvents mixture is calculated according to Equation (2) (Jouyban and Soltanpou, 2010) and resumed in Table 4.

$$
\varepsilon=\left(\frac{\% \text { water }}{100} \cdot \varepsilon_{\text {water }\left(25^{\circ} \mathrm{C}\right)}\right)+\left(\frac{\% \text { ethanol }}{100} \cdot \varepsilon_{\text {ethanol }\left(25^{\circ} \mathrm{C}\right)}\right)
$$

The dielectric constant increases with the ethanol concentration. The relationship between the constant and gold particle size is presented in Figure 3. It is clear how the dielectric constant of the mixture influences the size of the resulting gold nanoparticles, the lower the percentage of water the higher the average size of the nanoparticles. The colloid 50:50 is out of the described trend, higher particle size is observed contrary to the expected from the calculated dielectric constant. This synthesis was repeated several times, showing similar results. It is necessary to carry out an in-depth study to explain this unexpected result.

XRD analysis of the $\mathrm{Au} / \mathrm{C}$ catalysts (Table 1) obtained after gold colloids immobilization are presented in Figure 4. The diffractograms show reflections associated with metallic gold (ICDD 00-001-1172), carbon, quartz (ICDD 01-086-1628), and cristoballite (ICDD 00-004-0379) (the formers present in DARCO $^{\circledR}$ as impurities) (Santos et al., 2018b). The average gold crystallite size was calculated applying Scherrer's equation from the broadening of the (111) Au plane at $38.28^{\circ} 2 \theta$ (Table 5). All samples present average particle size in the $5-7 \mathrm{~nm}$ range. According to the average particle size of the colloids, higher the water proportion, lower the gold particle size.

More detailed analysis of the samples by TEM (Figure 5) reveal bigger particle size of the supported nanoparticles than the corresponding colloids, due to the sintering occurring

TABLE 4 | Average gold particle size (TEM), maximal absorbance wavelength $\lambda_{\max }$, SPR calculated area, dielectric constant of the used medium.

\begin{tabular}{lcccc}
\hline $\begin{array}{l}\text { Water:ethanol } \\
(\% \mathbf{v} / \mathbf{v})\end{array}$ & $\begin{array}{c}\text { Average gold } \\
\text { particle size, } \\
\text { TEM (nm) }\end{array}$ & $\begin{array}{c}\lambda \text { max, SPR } \\
\text { (nm) }\end{array}$ & $\begin{array}{c}\text { SPR calculated } \\
\text { area (a.u.) }\end{array}$ & $\begin{array}{c}\boldsymbol{\varepsilon} \text { at } \mathbf{2 5}^{\circ} \mathbf{C} \\
(\mathbf{F} / \mathbf{m})\end{array}$ \\
\hline 100:0 & $2.9 \pm 0.7$ & 523 & 230.84 & 78.54 \\
$70: 30$ & $3.6 \pm 0.9$ & 531 & 249.03 & 62.26 \\
$50: 50$ & $7.8 \pm 1.7$ & 537 & 339.46 & 51.41 \\
$30: 70$ & $4.5 \pm 1$ & 531 & 267.75 & 40.56 \\
$8: 92$ & $8.5 \pm 2$ & 540 & 313.27 & 28.62
\end{tabular}

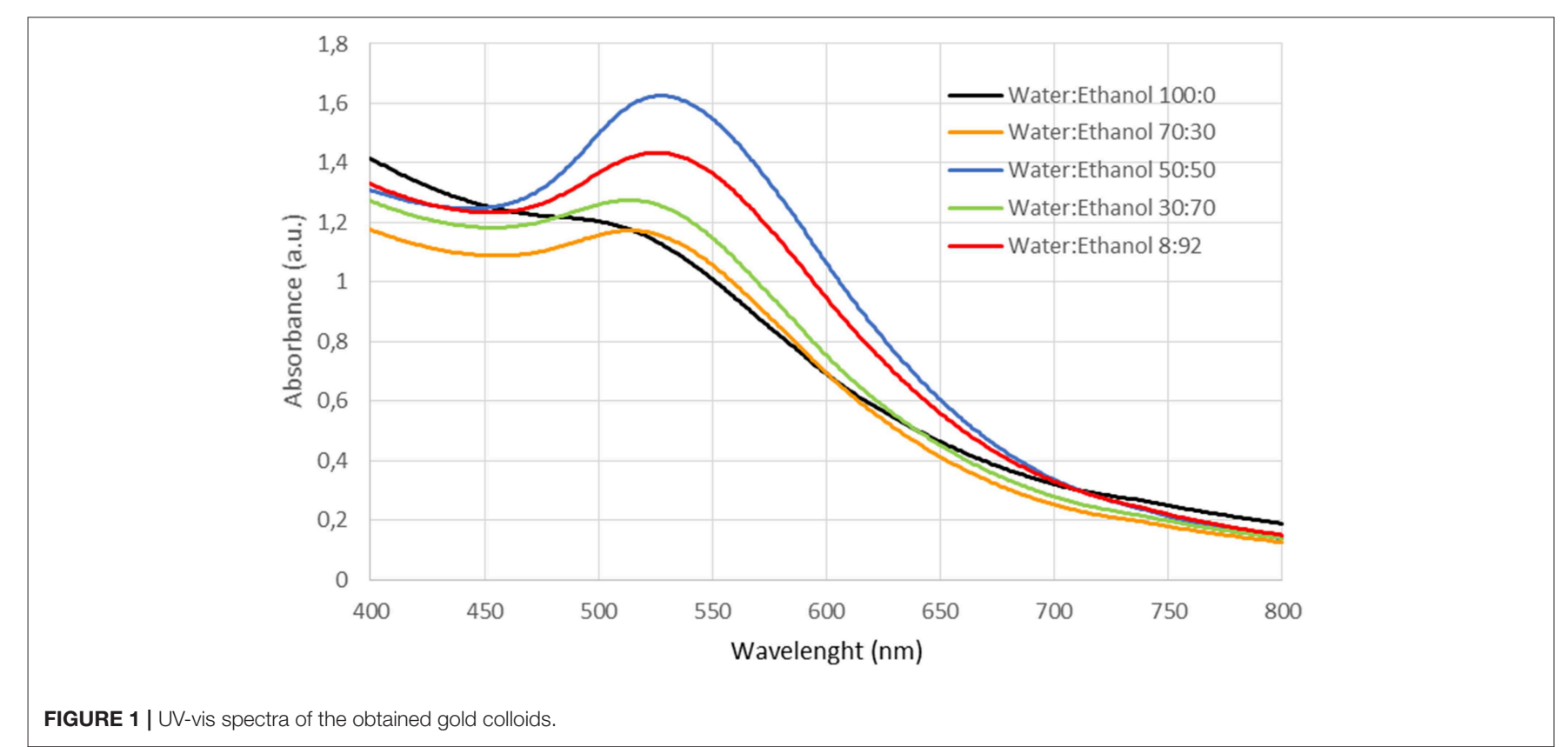




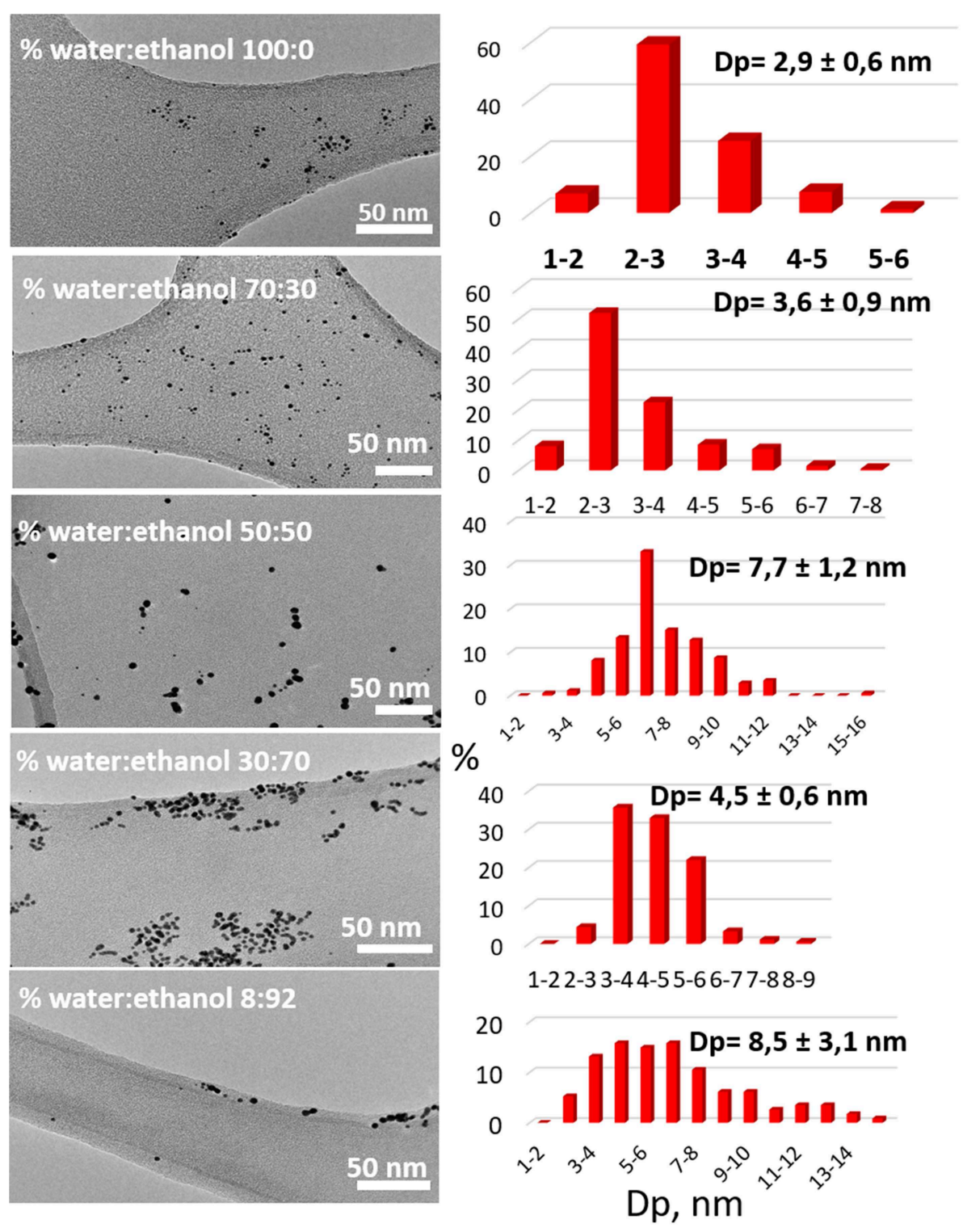

FIGURE 2 | TEM micrographs, particle size distribution, and average gold particle size (Dp) for the obtained colloids.

during calcination. It appears that the particle size distributions for the supported samples are less narrow than the one observed for colloids. The tendency observed by XRD and TEM are the same, however, when the size homogeneity is low and the number of measured particles by TEM not high enough, the obtained average size could imply an important error. That is why the Scherrer results are considered for all future discussions.

If we correlate the gold average size (obtained by XRD) with the percentage of water in the solvent mixture (Figure 6), we can see that size decreases when the water content in the mixture increases. This is somehow an expected result, since DARCO ${ }^{\circledR}$ is a hydrophilic carbon that should present stronger interaction with polar solvents, giving smaller particles size at higher water concentration.
The relationship between the gold average particles size in $\mathrm{Au} / \mathrm{C}$ catalysts (XRD) and in colloids (TEM) is also almost linear, with smaller the colloid size, smaller the size on catalyst surface. The transfer process does not seem to affect seriously the gold nanoparticles size.

\section{Calcination Process}

As explained in section Calcination process, six different calcination processes were applied (Table 2) to optimize the calcination step for the elimination of the protective agent (PVA) in order to obtain the smallest particle size. In all cases, the same $\mathrm{Au} / \mathrm{C}$ catalyst (Au/CD_100) was calcined at a constant final temperature $\left(300^{\circ} \mathrm{C}\right)$ and total gas flow $(30 \mathrm{~mL} / \mathrm{min})$.

As showcases in Figure 7 and Table 6, the calcination process clearly influences the gold nanoparticle size. According to the 
results gold particle size oscillates between 5 and $7 \mathrm{~nm}$ and varies with the oxygen concentration and treatment duration. For the same duration of calcination treatment, the particle size decreases proportionally to the oxygen concentration (methods 1 and 2). In fact, samples where the combustion step is carried out in synthetic air (methods 1 and 4) present bigger particle size. Moreover, neither the annealing process (methods 4 and 5) nor the reduction of the heating rate achieves lower particle sizes (methods 3 and 6). Method 3 that implies lower duration, i.e., low energy consumption is selected as the more adequate. In addition, the average particle size obtained for this sample is the smallest, according to TEM and XRD measurements. The application of this calcination procedure reduces sintering phenomena resulting in a minimal increase from 2.9 (colloid) to $4.6 \mathrm{~nm}$ (supported catalyst). All

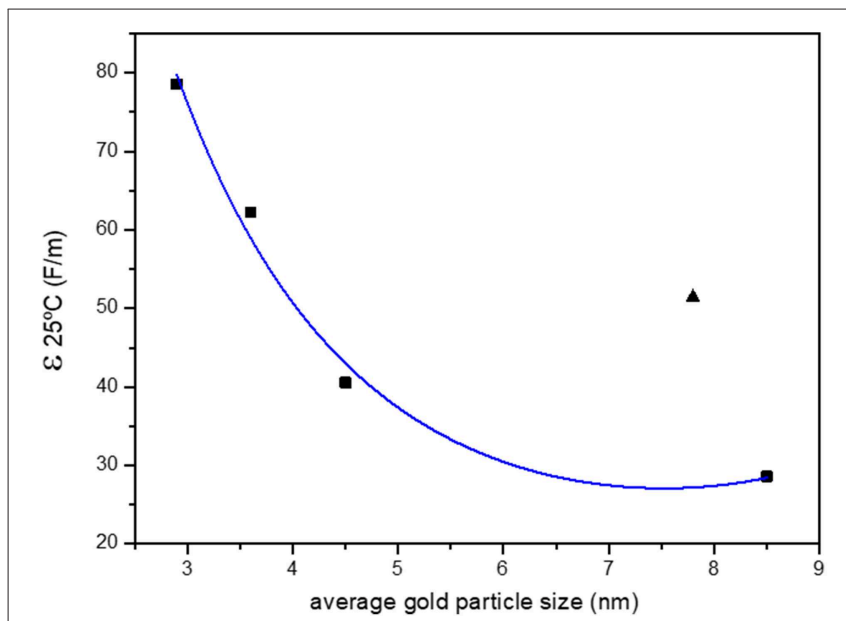

FIGURE 3 | Relationship of the average particle size with the dielectric constant of the solvent. samples calcined by the method 3 will be labeled from now on as Name_3.

\section{$\mathrm{Au} / \mathrm{C}$ Catalyst Over Different Charcoals Powder Support}

As described in section Au/C Catalyst over different charcoals powder support, a second series of $\mathrm{Au} / \mathrm{C}$ catalysts were synthetized employing diverse charcoal powders as supports and compared with $\mathrm{Au} / \mathrm{CD}$ catalysts.

The supports were selected in order to study the possibility to expand the horizons of the developed synthesis technique for a variety of carbonaceous materials with different hydrophilic character and functionalization degree. DRIFTS spectroscopy (Figure 8) was used for such evaluation, since it is able to detect the oxygenated functional groups on the carbon surface, providing determinant information about the surface chemical structure of the material (Meldrum and Rochester, 1991; Fanning and Vannice, 1993; Wang et al., 2019).

Along with the IR bands of aromatic and aliphatic carbons $\left(\mathrm{C}=\mathrm{C}\right.$ stretching vibration, $1,600 \mathrm{~cm}^{-1}$, $\mathrm{C}-\mathrm{C}$ stretching vibrations, $1,450 \mathrm{~cm}^{-1}, \mathrm{C}-\mathrm{H}$ of aliphatic chains around 2,900 $\left.\mathrm{cm}^{-1}\right)$, C-H of aromatic compounds $\left(3,040 \mathrm{~cm}^{-1}\right)$, and C$\mathrm{H}$ out of plane vibrations of substituted benzene rings (750 and $950 \mathrm{~cm}^{-1}$ ) (Lin-Vien et al., 1991), all solids present bands characteristics of several oxygenated functional groups. Those

TABLE 5 | Gold nanoparticles average size of the Au/C catalysts obtained by TEM and XRD.

Catalyst Average size, TEM (nm) S\&M Average size, XRD (nm)

$\mathrm{Au} / \mathrm{CD}_{-} 100 \quad 8.3 \pm 1 \quad 5.3$

$\mathrm{Au} / \mathrm{CD}_{-} 70 \quad 9.6 \pm 1.6 \quad 5.9$

$\begin{array}{lll}\mathrm{Au} / \mathrm{CD} \_50 & 12.1 \pm 3.8 & 6.8\end{array}$

$\begin{array}{lll}\text { Au/CD_30 } & 7.4 \pm 0.7 & 6.2\end{array}$

$\begin{array}{lll}\mathrm{Au} / \mathrm{CD} \_8 & 11.8 \pm 1.7 & 7.0\end{array}$

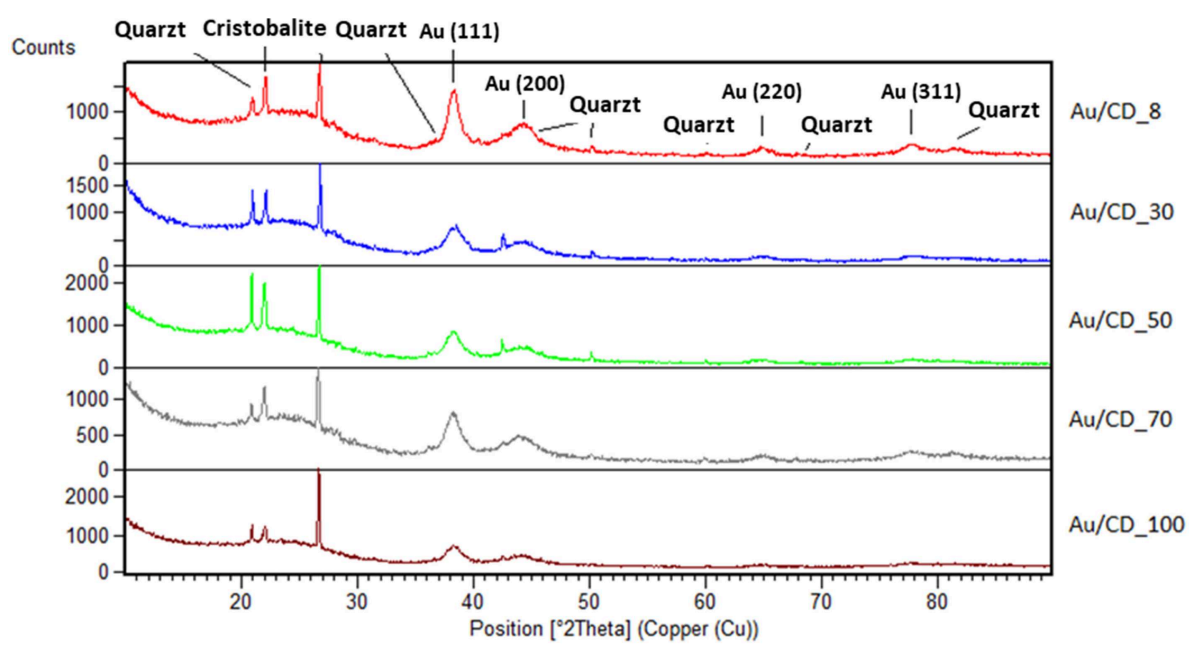

FIGURE 4 | Au/C catalysts diffractograms. 

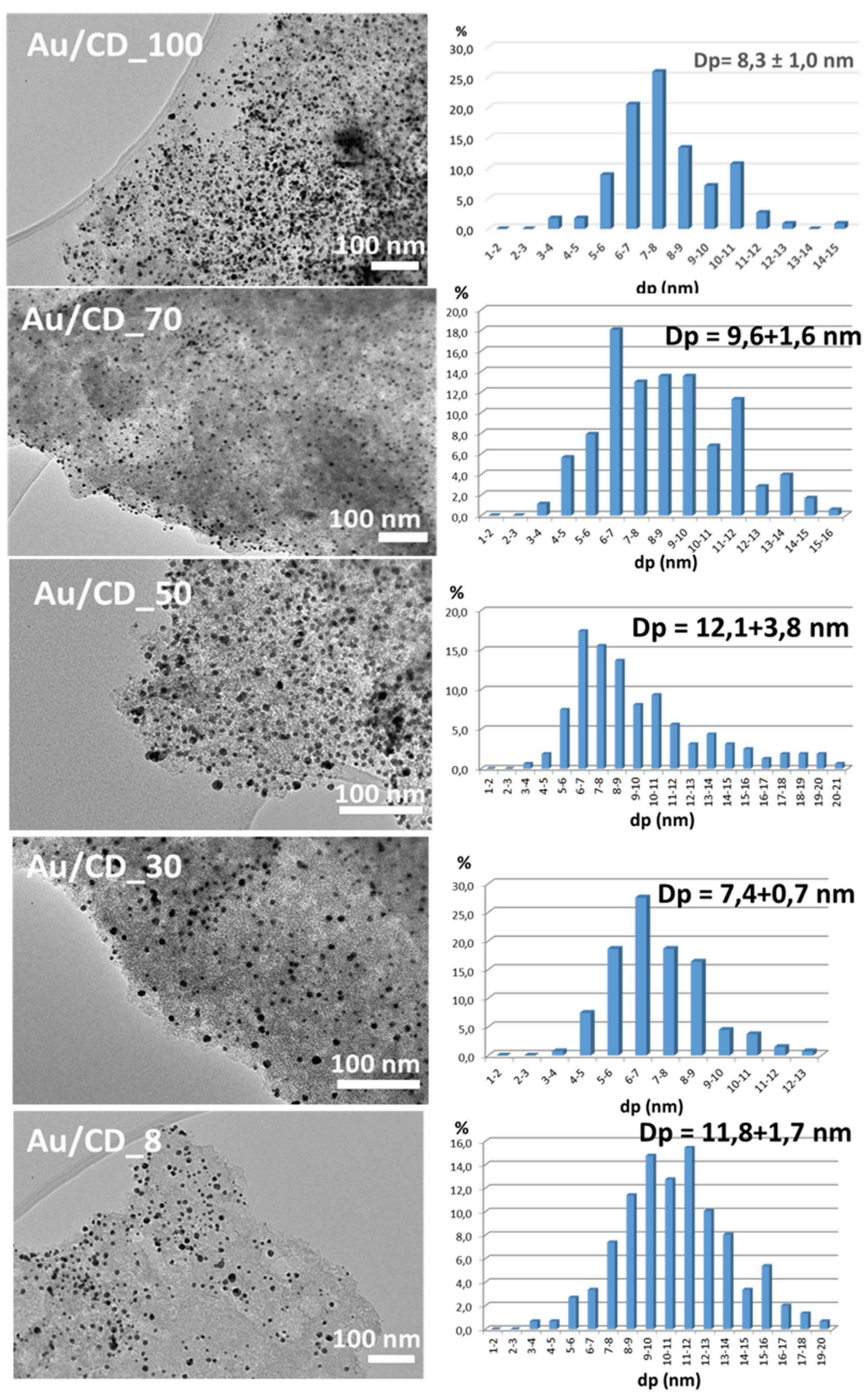

FIGURE 5 | TEM micrographs and gold particle size for Au/C catalysts.

bands, in the $1,030-1,300 \mathrm{~cm}^{-1}$ region, are indicative of C$\mathrm{O}$ single bond of different oxygenated groups such as esters $\left(1,150-1,250 \mathrm{~cm}^{-1}\right)$, acidic and cyclic anhydrides $(1,180-1,300$ $\left.\mathrm{cm}^{-1}\right)$, lactones $\left(1,160-1,370 \mathrm{~cm}^{-1}\right)$, ethers $\left(1,120-1,300 \mathrm{~cm}^{-1}\right)$, cyclic ethers $\left(1,140 \mathrm{~cm}^{-1}\right)$, phenolic groups $\left(1,180-1,220 \mathrm{~cm}^{-1}\right)$, epoxides $\left(1,220 \mathrm{~cm}^{-1}\right)$, etc. Besides this, an intense band a 1,730 $\mathrm{cm}^{-1}$ due to $\mathrm{C}=\mathrm{O}$ aldehyde groups is clearly visible. In the case of the CC charcoal, a band centered at $1,900 \mathrm{~cm}^{-1}$ corresponding 


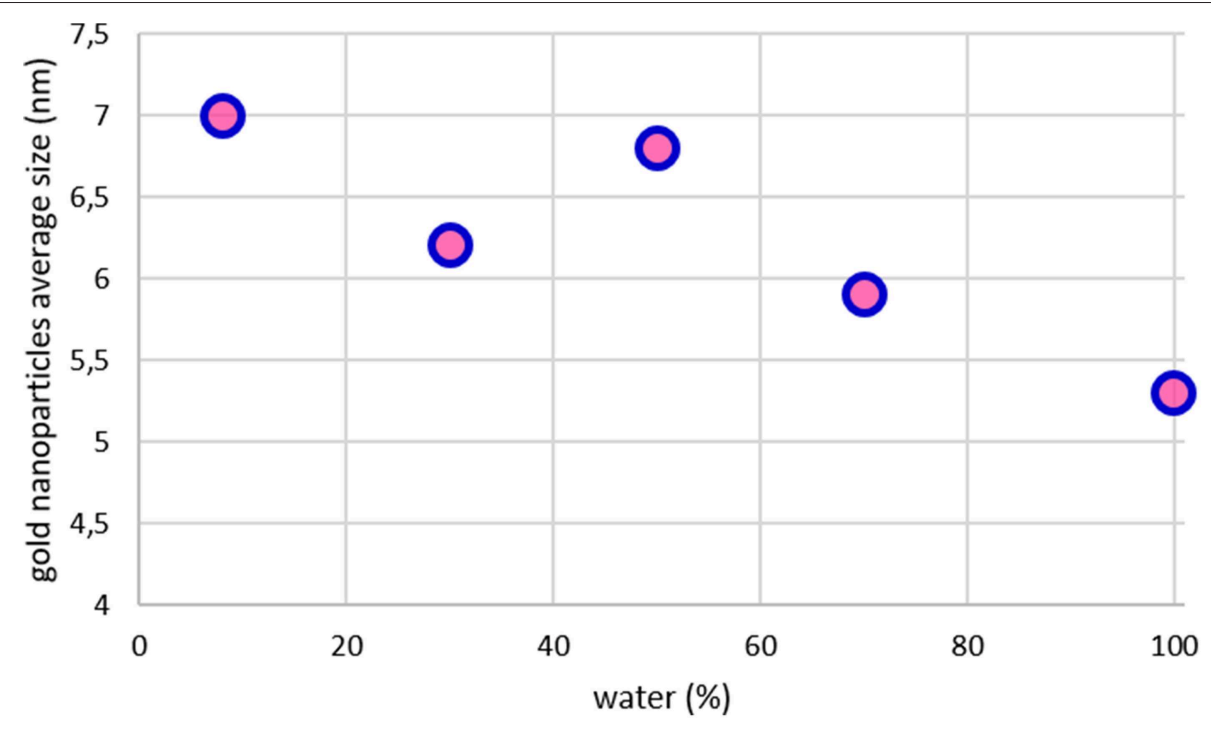

FIGURE 6 | Relationship of the gold average particle size with the water percentage of the solvent.

probably to lactones (Lin-Vien et al., 1991; Meldrum and Rochester, 1991; Fanning and Vannice, 1993; Wang et al., 2019) is also detected, together with very intense bands of substituted aromatic rings $\left(3,040 \mathrm{~cm}^{-1}\right.$, between 1,000 and $1,300 \mathrm{~cm}^{-1}$ and between 750 and $950 \mathrm{~cm}^{-1}$ ).

The wide band between 3,200 and $3,600 \mathrm{~cm}^{-1}$ is due probably to the $\mathrm{O}-\mathrm{H}$ vibrations of water adsorbed on the superficial functional groups. In order to classify the compounds according to their degree of functionalization (Daud and Houshamnd, 2010), the band at $1,730 \mathrm{~cm}^{-1}$ of the carbonyls groups was taken as reference. The intensity of this band could be correlated to the degree of superficial hydrophilicity, i.e., high intensity of the band corresponds to greater functionalization and hydrophilia. The hydrophilicity decreases in order: $\mathrm{CSA}>\mathrm{CD}>\mathrm{CS}>\mathrm{CC}$.

This is a reasonable order, taking into account the different provenance and nature of the studied charcoals. Thus, the CC one obtained by pyrolysis in $\mathrm{CO}_{2}$ atmosphere from commercial microcrystalline cellulose (Santos et al., 2018a), without any kind of functionalization, or presence of inorganic material, present a marked hydrophobic character. The CS sample, obtained by a similar pyrolysis process, comes from a natural lignocellulosic biomass (vine shoot), with different oxygen content and inorganic compounds in its structure. Prior to the pyrolysis CS sample undergoes a demineralization treatment with nitric acid, which contributes to a certain oxidation of the organic matter. It can be expected, therefore, that the obtained carbon presents higher oxygen content, reflecting in higher hydrophilicity. Finally, both, commercial activated carbon (CD) and CSA charcoals, activated after pyrolysis in nitric acid, contain greater percentage of oxidized surface groups, and consequently greater hydrophilic character.

Based on the observed hydrophilic properties of the samples, different water-ethanol mixtures were used (Table 3) to prepare the second series of catalysts, high ethanol concentration for the most hydrophobic ones and vice versa.

The average gold particle size of the catalysts measured by XRD is shown in Table 7. Very interesting observation arises, the hydrophobicity of the support is directly related to the solvent mixture and to the final particle size. As long as more ethanol is used for the hydrophobic samples (Au/CC_8_3 vs. Au/CC_30_3) and more water for the hydrophilic ones (Au/CSA_30_3 vs. Au/CSA_100_3) the average particle size decreases. Even more, for Au/CSA_100_3 sample no gold diffractions are observed indicating gold average particle size below the detection limit of the technique. For CS, which has an intermediate hydrophilic character, no obvious correlation is observed.

Comparing the average gold particles size for the catalysts synthetized in water only for different charcoals as supports, the sizes sequence follows the hydrophilicity degree: Au/CSA_100_3 (below the detection limit) <Au/CD_100_3 (3.7 nm) < Au/CS_100_3 (4.6 nm).

The results evidence that, despite that the alcohol media disfavors obtaining of gold colloids with lower sizes, its use can be beneficial if the carbonaceous material presents an important hydrophobic character.

\section{Catalytic Tests: 4-Nitrophenol Reduction}

For the reduction of 4-nitrophenol, two samples from the first series are used $\mathrm{Au} / \mathrm{CD} \_100 \_3$ and $\mathrm{Au} / \mathrm{CD} \_8 \_3$ as representatives of the most different gold average particle size, 6.5 and $11.8 \mathrm{~nm}$, respectively. The selected catalysts are useful to study how the gold particle size influences the rate constant of the reaction, with the 4-NP to 4-AP transformation monitored by UV-Visible absorption spectroscopy.

The characteristic absorption peak of 4-NP is located around $317 \mathrm{~nm}$. When $\mathrm{NaBH}_{4}$ is added to 4-NP, in absence of catalyst, 

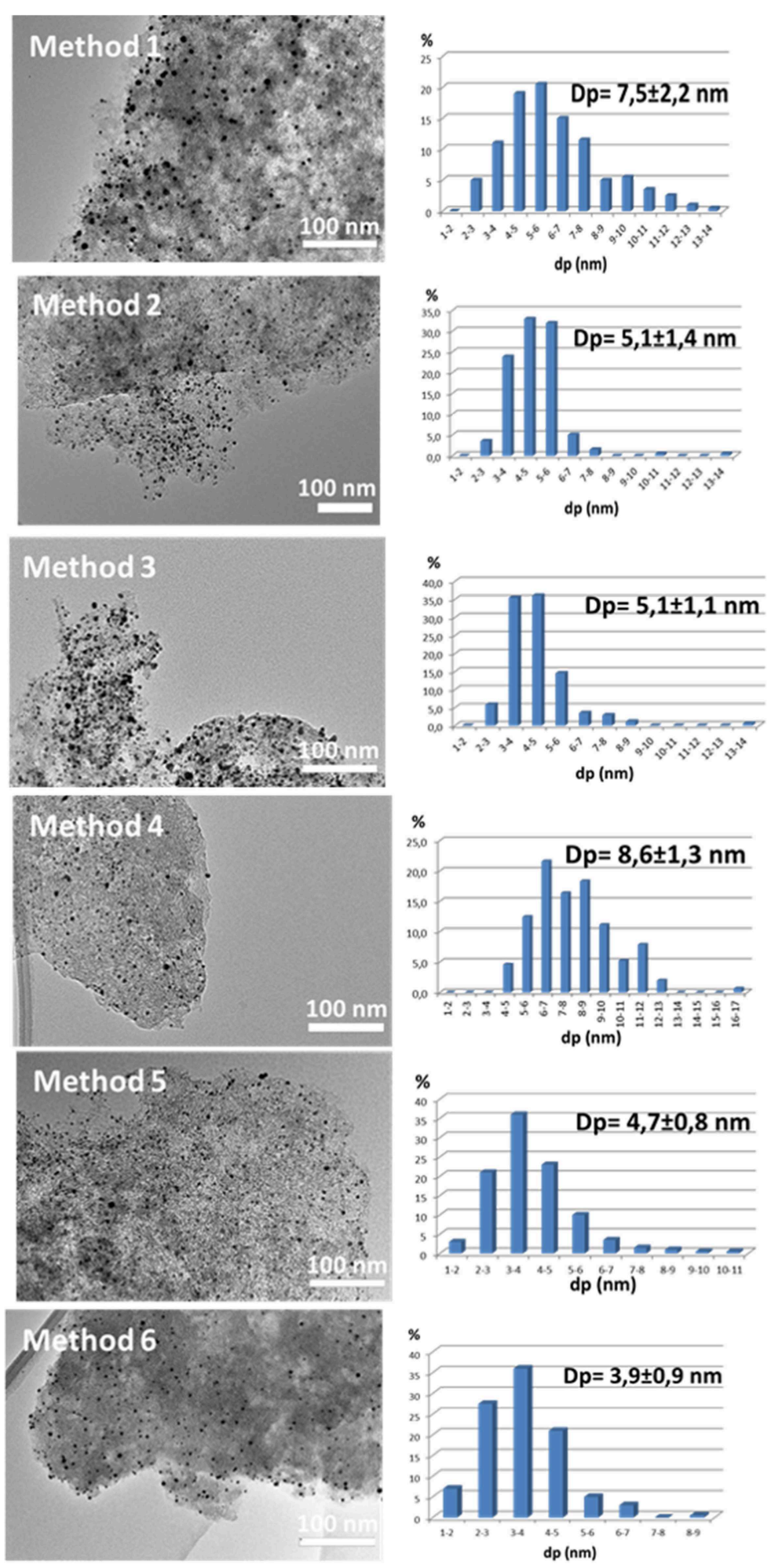

FIGURE 7 | TEM micrographs and gold particle size distribution for Au/C catalysts obtained with different calcination methods.

a color modification of the solution from light to dark yellow is immediately observed, accompanied by a shift in the peak position from 317 to $400 \mathrm{~nm}$. This evolution is associated with the formation of 4-nitrophenolate anions (Berahim et al., 2018). When catalyst is present into the solution the absorption at $400 \mathrm{~nm}$ decreases, while a new signal around $300 \mathrm{~nm}$ appears, 
TABLE 6 | Average gold particle size of the Au/C catalyst obtained with different calcination methods.

\begin{tabular}{lcc}
\hline Method & $\begin{array}{c}\text { Average gold particle size, } \\
\text { TEM (nm) }\end{array}$ & $\begin{array}{c}\text { Average gold particle size, } \\
\text { DRX (nm) }\end{array}$ \\
\hline 1 & $7.5 \pm 2.2$ & 5.2 \\
2 & $5.1 \pm 1.4$ & 3.9 \\
3 & $5.1 \pm 1.1$ & 3.7 \\
4 & $8.6 \pm 1.3$ & 5.0 \\
5 & $4.7 \pm 0.8$ & 4.2 \\
6 & $3.9 \pm 0.9$ & 4.3
\end{tabular}

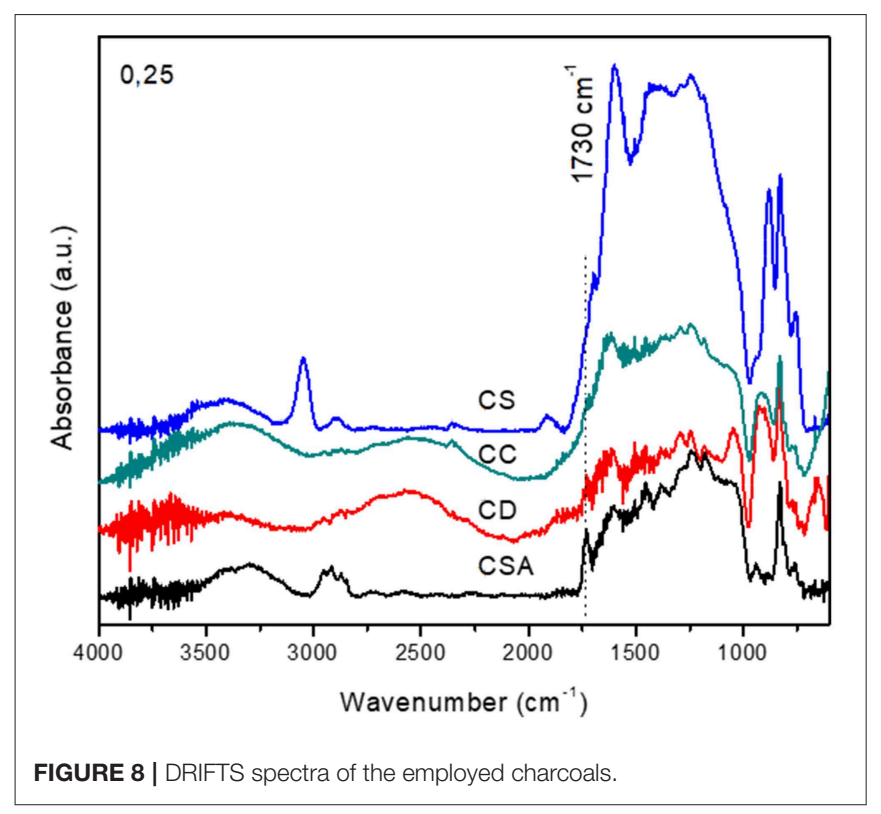

TABLE 7 | Average gold nanoparticles size for the Au/C catalysts.

\begin{tabular}{lc}
\hline Catalyst & Gold nanoparticles size XRD, nm \\
\hline Au/CC_8_3 & 7.2 \\
Au/CC_30_3 & 8.0 \\
Au/CS_8_3 & 5.5 \\
Au/CS_30_3 & 6.2 \\
Au/CS_100_3 & 4.6 \\
Au/CD_100_3 & 3.7 \\
Au/CSA_30_3 & 8.7 \\
Au/CSA_100_3 & - \\
\hline
\end{tabular}

increasing with time and associated with the reaction product, 4-AP (Figure 9). The presence of the isosbestic point around $320 \mathrm{~nm}$, indicates the reduction of 4-NP to 4-AP occurs without by-product formation (Berahim et al., 2018).

Since the concentration of $\mathrm{BH}_{4}^{-}$is much higher than that of 4-NP, it can be assumed that the borohydride concentration remains constant during the reaction (Berahim et al., 2018) and the reaction follows pseudo-first order kinetics given by the

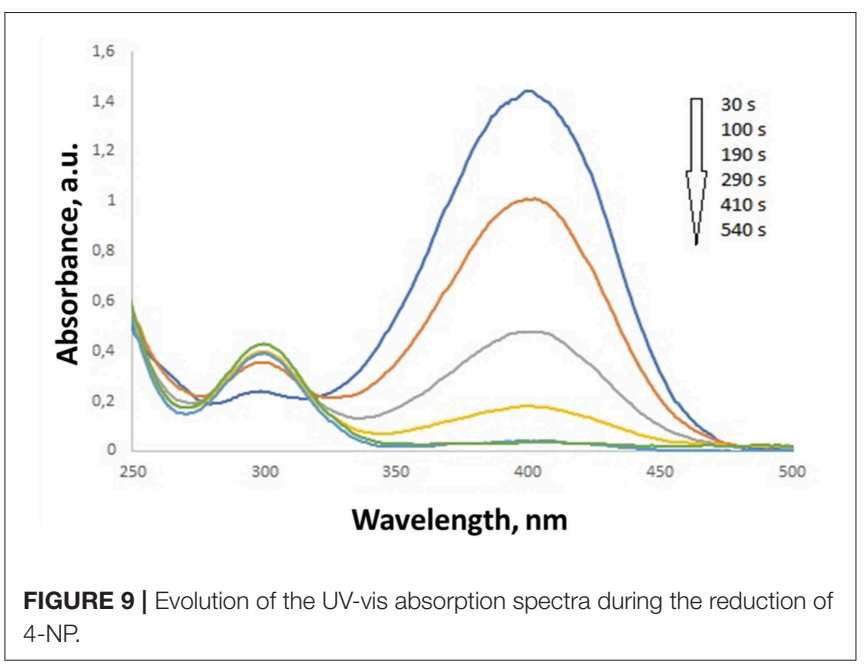

Equation (3),

$$
\frac{C}{C_{0}}=\exp (-k t)
$$

where $\mathrm{C}_{0}$ and $\mathrm{C}$ represent the initial and final concentrations of $4-\mathrm{NP}, \mathrm{t}$ symbolizes the reaction time and $\mathrm{k}$ denotes the rate constant.

To calculate the rate constant of the 4-NP reduction reaction, the variation of its concentration with time is studied. A linear correlation is observed between $\ln \left(\mathrm{C} / \mathrm{C}_{0}\right)$ and time, obtaining the rate constant from the slope of this graph (Figure 10). Three catalytic tests are realized for each sample, showing high reproducibility. The calculated rate constant is obtained after averaging the three values.

For the Au/CD_8_3 catalysts, with an average gold particle size of $11.8 \mathrm{~nm}$ ( $7 \mathrm{~nm}$ XRD), the value of the obtained rate constant is $k=8.90 \times 10^{-3} \mathrm{~s}^{-1}\left(0.534 \mathrm{~min}^{-1}\right)$, while for the $\mathrm{Au} / \mathrm{CD} \_100 \_3$, with size average of $8.3 \mathrm{~nm}$ (5.3 nm XRD), rate constant increases to $k=1.10 \times 10^{-2} \mathrm{~s}^{-1}\left(0.660 \mathrm{~min}^{-1}\right)$. Hence the impact of gold particle size in the reaction kinetics is clearly evidenced in view of these results. Essentially smaller the gold nanocrystals size higher the increase the 4-NP reduction rate. The rate constant obtained for both catalysts present superior values for similar noble based catalyst (Table 8). It appears that the carbonaceous support is not as important as gold particles size or doping. The presence of graphene oxide does not promote the gold action and for a similar size the use of activated carbon seems better (our study), probably due to the higher surface area of the latter. On the other hand, the doping of gold with silver presents a beneficial effect and results in higher rate constants.

The reaction mechanism (Langmuir-Hinshelwood) is frequently related to the electron transfer from $\mathrm{NaBH}_{4}$ to $4-\mathrm{NP}$ adsorbed on the same active site (Wunder et al., 2010, 2011). The metal surface assures the necessary sites for adsorption and transfer of electrons. It is then logical to consider that greater 


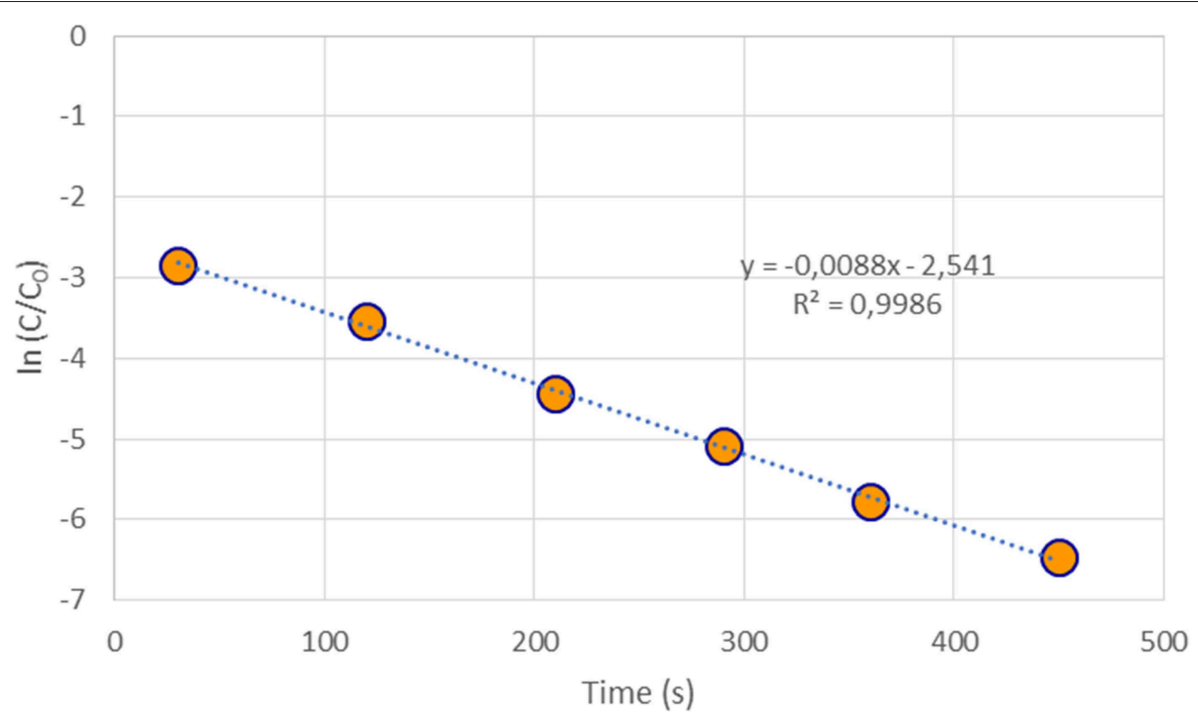

FIGURE 10 | In (C/C $)$ vs. time for 4-NP reduction using Au/CD_8 as catalyst.

TABLE 8 | Comparison of the catalytic reduction of 4-NP by different noble metal catalysts.

\begin{tabular}{lccl}
\hline Catalyst & $\begin{array}{c}\text { Rate constant } \\
\left(\mathbf{m i n}^{-1} \mathbf{)}\right.\end{array}$ & $\begin{array}{c}\text { Particle size } \\
(\mathbf{n m})\end{array}$ & References \\
\hline Au/CD_8_3 & 0.534 & 7.0 & Reference \\
Au/CD_100_3 & 0.660 & 5.3 & This work \\
Au NPs & 0.360 & 24.1 & This work \\
Au-Ag NPs & 0.620 & 55.2 & Berahim et al., 2018 \\
Ag/GO NPs & 0.208 & 7.5 & Berahim et al., 2018 \\
Au/GO NPs & 0.368 & 5.0 & Wu et al., 2013 \\
Au-Ag/GO NPs & 0.761 & 6.0 & Wu et al., 2013 \\
Pd-graphene nanohybrids & 0.197 & 17.0 & Wang et al., 2014 \\
\hline
\end{tabular}

the exposed surface area higher the rate of electron transfer and higher the rate constant of 4-NP reduction.

It is clear, in our case that the reaction rate depends on the number of exposed gold sites, for gold particles on the same support. On the other hand, the gold dispersion depends on the optimization of the synthetic parameters as solvent, support nature and calcination procedure. Although the gold colloid preparation appears as an easy task, its immobilization is much more complicated. The nature of the support when referring to carbon is one of the most important parameters to take into account. Hydrophobic carbons force the use of less polar solvents as ethanol, which reflects in an increase of the initial colloid size as the latter is smaller when more polar solvents are used (water). Referring to the calcination procedure the most important parameter is the atmosphere of calcination more precisely the oxygen concentration. Lower the oxygen concentration, lower the particle size. The heating rate and duration are not so relevant and could be chosen as compromise between size and energy and time savings.

\section{CONCLUSIONS}

This work showcases a flexible strategy to prepare nanogold based catalysts via colloids transfer to suitable supportsactivated carbons in particular. Water: Ethanol mixtures has been selected as reference solvents for the synthesis. Indeed, there is a remarkable impact of solvent on the average gold particle size in the colloids in such a way that when the amount of ethanol in the solvent mixture increases, the average gold particle size increases. An anomalous behavior is observed for a 50:50 mixture. In fact, the affinity of the support for water is also a factor to consider where the solvent can tune the resulting catalysts' features. Depending on hydrophilicity of the support the water:ethanol ratio could be adjusted to obtain the smallest average gold particle size.

A successful transfer of the colloid nanoparticles to commercial hydrophilic activated charcoal is obtained. The final gold particle size is superior to that of colloids due to sintering, with the smallest one obtained for the Au/CD_100 (prepared in water).

Oxygen presence in the thermal treatment also has a marked effect on the resulting catalysts. We observed that tower the concentration of oxygen during the treatment lower the particle size and hence higher exposed active surface for the reaction. Among the different thermal treatments carried out in order to remove the organic protective agent, PVA, the optimal one is: $300^{\circ} \mathrm{C}$, an oxidative flow of $30 \mathrm{~mL} / \mathrm{min}$ of $\mathrm{N}_{2}$ synthetic air mixture ( $2 \%$ S.A.) for $30 \mathrm{~min}$ and a heating rate of $10^{\circ} \mathrm{C} / \mathrm{min}$. 
Finally, the as prepared gold based catalysts has demonstrated their efficiency for environmentally relevant catalytic reactions i.e., the reduction of 4 -NP. In the process, the average gold particle size of the $\mathrm{Au} / \mathrm{C}$ catalyst influences the kinetics of the reaction, in such a way that, smaller the gold particle size, higher the constant rate.

\section{DATA AVAILABILITY}

The datasets generated for this study are available on request to the corresponding author.

\section{REFERENCES}

Alif, A., and Boule, P. (1991). Photochemistry and environment Part XIV. Phototransformation of nitrophenols induced by excitation of nitrite and nitrate ions. J. Photochem. Photobio. A 59, 357-367. doi: 10.1016/1010-6030(91)87087-C

Berahim, N., Basirun, W. J., Leo, B. F., and Johan, M. R. (2018). Synthesis of bimetallic gold-silver (Au-Ag) nanoparticles for the catalytic reduction of 4-nitrophenol to 4-aminophenol. Catalysts 18:412. doi: 10.3390/catal8100412

Bond, G. C., and Thompson, D. T. (1999). Catalysis by gold. Catal. Rev. 41, 319-388. doi: 10.1081/CR-100101171

Chairam, S., Konkamdee, W., and Parakhun, R. (2017). Starch-supported gold nanoparticles and their use in 4-nitrophenol reduction. J. Saudi Chem. Soc. 21, 656-663. doi: 10.1016/j.jscs.2015.11.001

Chatterjee, D., and Dasgupta, S. (2005). Visible light induced photocatalytic degradation of organic pollutants. J. Photochem. Photobio. C 6, 186-205. doi: 10.1016/j.jphotochemrev.2005.09.001

Daud, W., and Houshamnd, A. (2010). Textural characteristics, surface chemistry and oxidation of activated carbon. J. Nat. Gas Chem. 19, 267-279. doi: 10.1016/S1003-9953(09)60066-9

Du, Y., Chen, H., Chen, R., and Xu, N. (2004). Synthesis of p-aminophenol from p-nitrophenol over nano-sized nickel catalysts. Appl. Catal. A 277, 259-264. doi: 10.1016/j.apcata.2004.09.018

Fanning, P. E., and Vannice, M. A. (1993). A DRIFTS study of the formation of surface groups on carbon by oxidation. Carbon 31, 721-730. doi: 10.1016/0008-6223(93)90009-Y

Goesmann, H., and Feldmann, C. (2010). Nanoparticle functional materials. Angew. Chem. Int. 49, 1362-1395. doi: 10.1002/anie.200903053

Harrison, M. A., Barra, S., Borghesi, D., Vione, D., Arsene, C., and Olariu, R. I. (2005). Nitrated phenols in the atmosphere: a review. Atmos. Environ. 39, 231-248. doi: 10.1016/j.atmosenv.2004.09.044

Hervés, P., Pérez-Lorenzo, M. M., Liz-Marzán, L., Dzubiella, J., Lu, Y., and Ballauff M. (2012). Catalysis by metallic nanoparticles in aqueous solution: model reactions. Chem. Soc. Rev. 41, 5577-5587. doi: 10.1039/c2cs35029g

Jouyban, A., and Soltanpou, S. (2010). Prediction of dielectric constants of binary solvents at various temperatures. J. Chem. Eng. Data 55, 2951-2963. doi: $10.1021 /$ je1000632

Kuoda, K., Ishida, T., and Haruta, M. (2009). Reduction of 4-nitrophenol to 4aminophenol over Au nanoparticles deposited on PMMA. J. Mol. Catal. A 298, 7-11. doi: 10.1016/j.molcata.2008.09.009

Lin, F. H., and Doong, R. A. (2014). Highly efficient reduction of 4-nitrophenol by heterostructured gold-magnetite nanocatalysts. Appl. Catal. A Gen. 486, 32-41. doi: 10.1016/j.apcata.2014.08.013

Lin-Vien, D., Colthup, N. B., Fateley, W. G., and Grasselli, J. G. (1991). "Chapter 13 - Cumulated double bonds," in The Handbook of Infrared and Raman Characteristic Frequencies of Organic Molecules, eds D. Lin-Vien, N. B. Colthup, W. G. Fateley, and J. G. Grasselli (San Diego, CA: Academic Press), 213-223.

Luo, J., Chu, W., Sall, S., and Petit, C. (2013). Facile synthesis of monodispersed $\mathrm{Au}$ nanoparticles-coated on Stöber silica. Colloids Surf. A 425, 83-91. doi: 10.1016/j.colsurfa.2013.02.056

\section{AUTHOR CONTRIBUTIONS}

All authors listed have made a substantial, direct and intellectual contribution to the work, and approved it for publication.

\section{FUNDING}

Financial support for this work has been obtained from the Spanish Ministerio de Ciencia, Innovación y Universidades (ENE2017-82451-C3-3-R) co-financed by FEDER funds from the European Union.

Megías-Sayago, C., Santos, J. L., Ammari, F., Chenouf, M., Ivanova, S., Centeno, M. A., et al. (2018). Influence of gold particle size in $\mathrm{Au} / \mathrm{C}$ catalysts for base-free oxidation of glucose. Catal. Today 306, 183-190. doi: 10.1016/j.cattod.2017.01.007

Meldrum, B. J., and Rochester, C. H. (1991). Infrared spectra of carbonaceous chars under carbonization and oxidation conditions. Fuel 70, 57-63. doi: 10.1016/0016-2361(91)90095-R

Menumerov, E., Hughes, R. A., and Neretina, S. (2016). Catalytic reduction of 4-nitrophenol: a quantitative assessment of the role of dissolved oxygen in determining the induction time. Nano Lett. 16, 7791-7797. doi: 10.1021/acs.nanolett.6b03991

Rodríguez-Reinoso, F. (1998). The role of carbon materials in heterogeneous catalysis. Carbon 36:159. doi: 10.1016/S0008-6223(97)00173-5

Saha, S., Pal, A., Kundu, S., Basu, S., and Pal, T. (2009). Photochemical green synthesis of calcium-alginate-stabilized $\mathrm{Ag}$ and $\mathrm{Au}$ nanoparticles and their catalytic application to 4-nitrophenol reduction. Langmuir 26, 2885-2893. doi: 10.1021/la902950x

Santos, J. L., Alda-Onggar, M., Fedorov, V., Peurla, M., Eränen, K., Mäki-Arvela, P., et al. (2018b). Hydrodeoxygenation of vanilin over carbon supported metal catalysts. Appl. Catal. A Gen. 561, 137-149. doi: 10.1016/j.apcata.2018. 05.010

Santos, J. L., Bobadilla, L. F., Centeno, M. A., and Odriozola, J. A. (2018a). Operando DRIFTS-MS study of WGS and rWGS reaction on biochar-based Pt catalysts: promotional effect of Na. J. Carbon Res. 4:47. doi: 10.3390/c40 30047

Shi, F., Zhang, Q., Ma, Y., He, Y., and Deng, Y. (2005). From CO oxidation to $\mathrm{CO} 2$ activation: an unexpected catalytic activity of polymersupported nanogold. J. Am. Chem. Soc. 127, 4182-4183. doi: 10.1021/ja0 42207 o

Tan, C., Huang, X., and Zhang, H. (2013). Synthesis and applications of graphene-based noble metal nanostructures. Mater. Today 16, 29-36. doi: $10.1016 /$ j.mattod.2013.01.021

Wang, J., Shen, B., Kang, D., Yuan, P., and Wu, C. (2019). Investigate the interactions between biomass components during pyrolysis using in-situ DRIFTS and TGA. Chem. Eng. Sci. 195, 767-776. doi: 10.1016/j.ces.2018. 10.023

Wang, Z., Xu, C., Gao, G., and Li, X. (2014). Facile synthesis of well-dispersed $\mathrm{Pd}$-graphene nanohybrids and their catalytic properties in 4-nitrophenol reduction. RSC Adv. 4, 13644-13651. doi: 10.1039/c3ra47721e

Wu, T., Zhang, L., Gao, J., Liu, Y., Gao, C., and Yan, J. (2013). Fabrication of graphene oxide decorated with $\mathrm{Au}-\mathrm{Ag}$ alloy nanoparticles and its superior catalytic performance for the reduction of 4-nitrophenol. J. Mater. Chem. A 1, 7384-7390. doi: 10.1039/c3ta10684e

Wunder, S., Lu, Y., Albrecht, M., and Ballauff, M. (2011). Catalytic activity of faceted gold nanoparticles studied by a model reaction: evidence for substrateinduced surface restructuring. ACS Catal. 1, 908-916. doi: 10.1021/cs200208a

Wunder, S., Polzer, F., Lu, Y., Mei, Y., and Ballauff, M. (2010). Kinetic analysis of catalytic reduction of 4-nitrophenol by metallic nanoparticles immobilized in spherical polyelectrolyte brushes. J. Phys. Chem. C 114, 8814-8820. doi: $10.1021 /$ jp $101125 \mathrm{j}$ 
Zhan, W., Shu, Y., Sheng, Y., Zhu, H., Guo, Y., Wang, L., et al. (2017). Surfactantassisted stabilization of $\mathrm{Au}$ colloids on solids for heterogeneous catalysis. Angew. Chem. 129, 4565-4456. doi: 10.1002/ange.201701191

Zhang, W., Xiao, X., An, T., Song, Z., Fu, J., Sheng, G., et al. (2003). Kinetics, degradation pathway and reaction mechanism of advanced oxidation of 4nitrophenol in water by a UV/H2O2 process. J. Chem. Technol. Biotechnol. 78, 788-794. doi: 10.1002/jctb.864

Zhao, B., Mele, G., Pio, I., Li, J., Palmisano, L., and Vasapollo, G. (2010). Degradation of 4- nitrophenol (4-NP) using Fe-TiO2 as a heterogeneous photo-Fenton catalyst. J. Hazard. Mater. 176, 569-574. doi: 10.1016/j.jhazmat.2009.11.066
Conflict of Interest Statement: The authors declare that the research was conducted in the absence of any commercial or financial relationships that could be construed as a potential conflict of interest.

Copyright (c) 2019 Rodríguez Molina, Santos Muñoz, Domínguez Leal, Reina, Ivanova, Centeno Gallego and Odriozola. This is an open-access article distributed under the terms of the Creative Commons Attribution License (CC BY). The use, distribution or reproduction in other forums is permitted, provided the original author(s) and the copyright owner(s) are credited and that the original publication in this journal is cited, in accordance with accepted academic practice. No use, distribution or reproduction is permitted which does not comply with these terms. 